\title{
BULGARIA'S DEFENCE POLICY AND FORCE SIZE FROM A COMPARATIVE MACRO PERSPECTIVE
}

\author{
Todor TAGAREV and Lidia VELKOVA
}

\begin{abstract}
The paper presents a novel, theoretically sound approach to the analysis of defence policy and force models and first results of its implementation. The approach is based on comparison of defence policies and cost data under the hypothesis that a particular defence policy relates to a specific set of defence capabilities with the respective impact on cost. We identified six factors, or dimensions, of defence policy with major impact on the cost of the respective capabilities, and used publicly available data to construct a model of capability cost, expressed in defence budget per active duty military personnel in constant purchasing power parity dollars, as a function of the six factors. Then the model was used to define what might be the reasonable force size of the Bulgarian Armed Forces in 2015 under three plausible alternative defence policies. The final section of the paper outlines strengths and limitations of the approach, as well as outputs and potential outcomes from its implementation.
\end{abstract}

Keywords: Capability costing, defence policy model, defence budget, purchasing power parity.

\section{Disclaimer}

The findings presented herein are result of reflections and analytical work of the authors and in no way can be interpreted as expression of the position of the "G.S. Rakovski" Defence and Staff College or any other governmental, intergovernmental or non-governmental organization. This work shall not be seen as a substitute of a rigorous, analytically sound force planning.

\section{Introduction}

In the face of increasing threats of international terrorism and frequency of natural disasters, some arguably as a consequence of global warming, security concerns of modern societies are shifting. Today, the anticipation is that, while preserving their lead role in the protection of sovereignty, independence and territorial integrity, armed forces will increasingly be expected to act decisively against non traditional 
threats originating at great distances from home bases, as well as to contribute to countering terrorist threats at home and the response to natural disasters and major industrial accidents.

Called to rise to this challenge, defence establishments around the world are in the process of transformation that should guarantee availability of a robust set of diverse capabilities of the armed forces in a timely manner. It would be trivial to state that the emphasis on capabilities to attack the terrorist threat at its roots in a comprehensive manner ${ }^{1}$ is costly. Cost has always been key, and occasionally "the key" consideration in the development of armed forces. Current costs of a proactive policy underscoring out-of-area operations are arguably higher than the costs of a more conventional, in place forces designed to deter enemies and, if deterrence fails, to react in a decisive manner. The diversification of capabilities and the flexibility also have a price. Attempts to maintain a balanced force structure during reductions of overall force size, especially for small- and mid-size countries, also lead to increasing unit costs. $^{2}$

This paper looks at costs of capabilities that relate to particular defence policies. We use statistical information on a number of countries that share the basic tenets of their defence policies - lack of a threat of a conventional aggression in the foreseeable future, understanding that threats should be dealt with proactively and comprehensively, sharing the burden among allies or strategic partners, etc.- - but differing in other respects. The statistical information is used to extract a model of capability costs, expressed in purchasing power parity (PPP) dollars spent per uniformed personnel, as a function of several key variables of the defence policy.

The first part of the paper presents our approach. The second part presents results of the reverse implementation of the model in support of the discussion of plausible models of Bulgaria's defence policy and the related force size. In the final part we discuss strengths and weaknesses of the approach, and the respective benefits and limits of its implementation. The conclusion underlines once again that this approach can add useful insight, but cannot substitute rigorous capabilities-oriented force planning as an integral part of the defence policy making.

\section{The Approach}

Traditionally, defence economists use macro indicators such as defence budget as a percentage of the GDP, military personnel as percentage of the population or of the labour force of a country, etc., to assess a particular defence policy. Defence expenditures per military personnel have been used to assess, comparatively, the level of capability of a military organization. ${ }^{3}$ Analysis of the distribution of defence expendi- 
tures by category - e.g. on personnel, operations and maintenance (O\&M), and investment—also provides useful insights.

Elaborating on these indicators, in a study on NATO enlargement Thomas Szayna accounted for the different purchasing power of the expenditures in different countries. ${ }^{4}$ One of the authors of this paper applied the approach while analysing alternative defence reform paths and the respective opportunities to develop requisite capabilities of Bulgaria's armed forces. ${ }^{5}$ These studies used defence expenditures, expressed in purchasing power parity (PPP) of the US dollar, divided by peacetime active force size as aggregated indicator for the level of capabilities the armed forces possess or plan to develop.

While useful, this indicator in itself does not allow accounting for the specifics of national defence policies and does not differentiate between purchasing "a basket of defence goods" from the general assessments of purchasing power parities.

The underlying hypothesis for this study is that force capabilities, required for the implementation of specific defence policies, have different costs. Therefore, defence spendings (in PPP\$) per troop are not directly comparable. Instead, a finer level of analysis is needed to reflect national specifics. The application of this hypothesis is based on the recognition that, while costs of capabilities to implement specific defence policies are different, comparative analysis may serve to assess current or planned capability levels.

Towards this purpose we selected a group of countries that share major defence policy tenets:

- Threat perceptions;

- Understanding on how threats should be dealt with;

- Willingness to approach the threats together with other countries (often expressed in treaties),

but differ in other respects, i.e. defence ambitions, traditional roles and societal expectations of the armed forces, manpower attitudes, technological and defence industrial ambitions, etc. And it is the specifics of national defence policies that require different sets of capabilities and, respectively, different spending levels.

We examine the specifics of defence policies along six "dimensions":

- Relative power;

- Technological level;

- Area focus;

- Mission spectrum; 
- Self-reliance;

- Manpower attitudes.

All selected dimensions have important resource implications and are briefly explained in the following paragraphs.

\section{Relative Power}

This is the capacity of the armed forces to exercise quickly considerable power over great distances. 'High' would be the score along this dimension for a military organization with considerable share of strategic forces, heavy armour and high-calibre artillery, heavy bomber, transport and tanker fleets, high-tonnage ships and submarines, satellite networks, etc. 'Low' would be the score for force structures with considerable share of light infantry units, special operations forces (SOF), etc.

\section{Technological Level}

This is the orientation in force development towards high-tech weapon systems, equipment, command and control (C2) and infrastructure. Force structures with most advanced weapon systems, C2 and supporting technologies would score highly along this dimension. Such score usually relates to ambitious defence industrial policy of a country. 'Low' would be the score for force structures with 'off-the-shelf' technology and considerable proportion of legacy equipment.

\section{Area Focus}

This is the capacity of a military organization to exercise/ participate in sustained 'out-of-area' operations versus traditional homeland defence missions. 'High' is the score for force structures 50 percent or more of which are deployable and 'low' for force structures with less that 10-15 percent deployable units and regular participation in 'out-of-area' operations with ad-hoc units (contingents).

\section{Mission Spectrum}

This dimension relates to the spectrum of operations and tasks accounted for in the force planning and force development processes. A force structure with broad spectrum of assigned military, homeland security ${ }^{6}$ and, in some cases, law enforcement missions will receive a high score along this dimension. 'Low' would be the score for force structures designed for 'traditional' military tasks, such as defensive and offensive actions against a military opponent; peace enforcement, and peacekeeping operations.

\section{Self-reliance}

This dimension was chosen to account for the scope of application of novel cost efficiency measures in a defence establishment. Force structures, relying on "in house" 
Table 1: Six Dimensions of the Defence Policy Model.

\begin{tabular}{|l|l|l|}
\hline Dimension & \multicolumn{2}{|c|}{ Prevailing features } \\
\hline Relative power & Light equipment & Heavy equipment \\
\hline Technological level & Low to Medium & High tech \\
\hline Area focus & Territorial defence & Expeditionary \\
\hline Mission spectrum & Societal security & Military missions \\
\hline Self-reliance & $\begin{array}{l}\text { Broad use of outsourcing, } \\
\text { cooperative procurement, } \\
\text { PPP, PFI, etc. }\end{array}$ & $\begin{array}{l}\text { Traditional, "in house" (for } \\
\text { self sustainment) capacity }\end{array}$ \\
\hline Manpower attitudes & Flexible, younger force & Life time career \\
\hline
\end{tabular}

capacity for all tasks, will score highly along this dimension. The score will be 'low' for force structures seeking efficiency through broad implementation of outsourcing, cooperative procurement programmes, public-private partnerships (PPP), private finance initiatives (PFI) and the like.

\section{Manpower Attitudes}

The last dimension of our defence policy model relates to the prevailing attitudes of military personnel towards their career. 'High' would be the score for a military organization that provides life-time career opportunities for the majority of service-men and women, with all respective social benefits. Force structures with more flexible and shorter term career models would receive a 'low' score.

Table 1 summarizes the presentation of the main variables in our defence policy model with the prevailing features at the extremes along each of the six dimensions.

\section{Sample Defence Policies}

In order to create the capability cost model, we use data on 17 countries-Australia, Bulgaria, Canada, Czech Republic, Denmark, France, Germany, Hungary, Italy, The Netherlands, Norway, Poland, Romania, Slovak Republic, Sweden, the United Kingdom, and the United States - that share essential defence policy premises, and data on their defence expenditures, military personnel strength, and purchasing power parities is readily available. $^{7}$ 


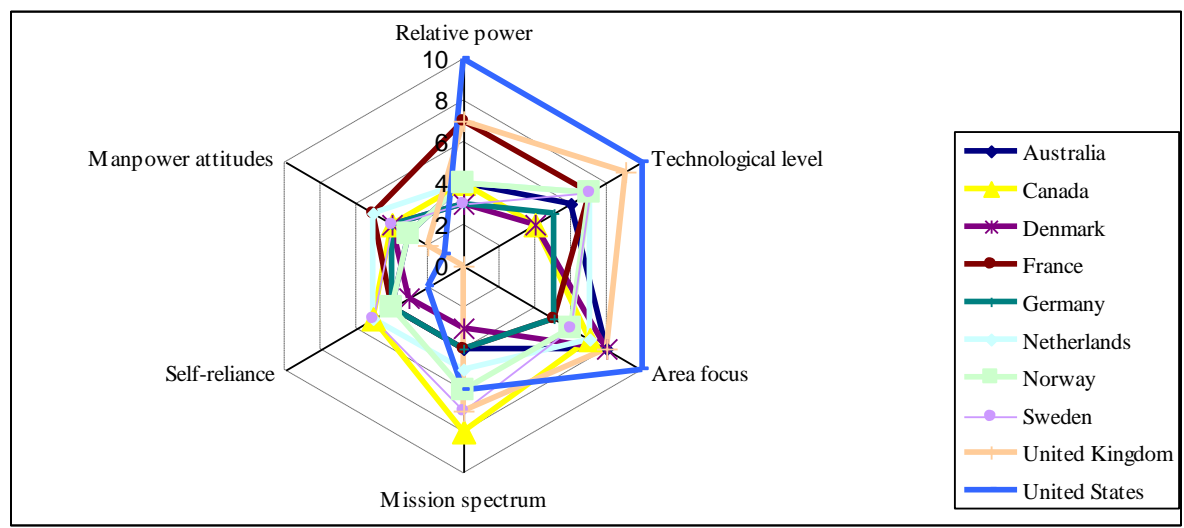

Figure 1: Top-right Heavy Defence Policy Models.
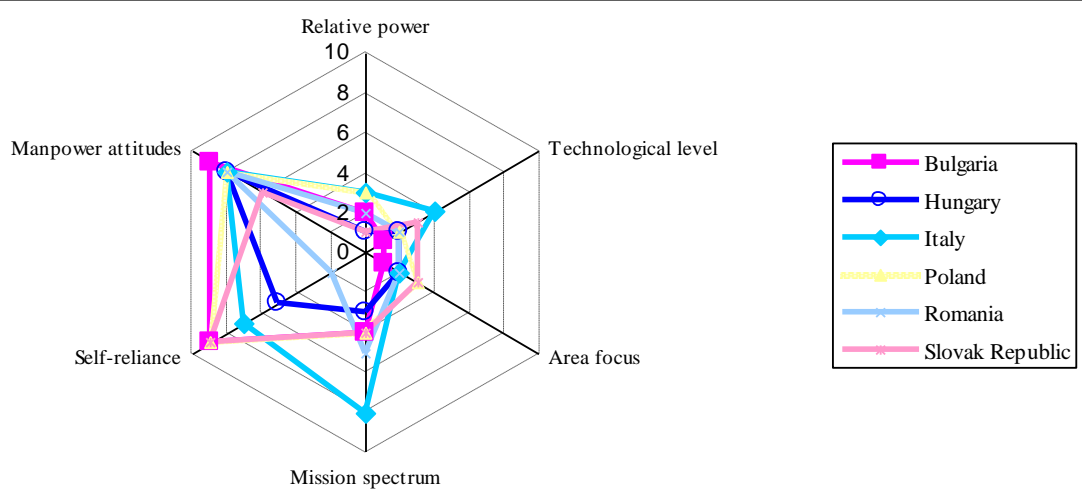

Figure 2: Bottom-left Heavy Defence Policy Models.

While similar in many respects, the defence policies of these countries differ considerably along the six dimensions of the model. Figures 1 and 2 provide radar chart representations of the defence policies of these countries, split in two groups for better visualization.

\section{Modelling Capability Costs}

Since the capabilities required to implement particular defence policies differ, the costs to realize these policies are also different and depend, in addition, on the economic situation and consumer prices in a country. Figure 3 presents the purchasing power of one US dollar in the 17 countries in 2005. 


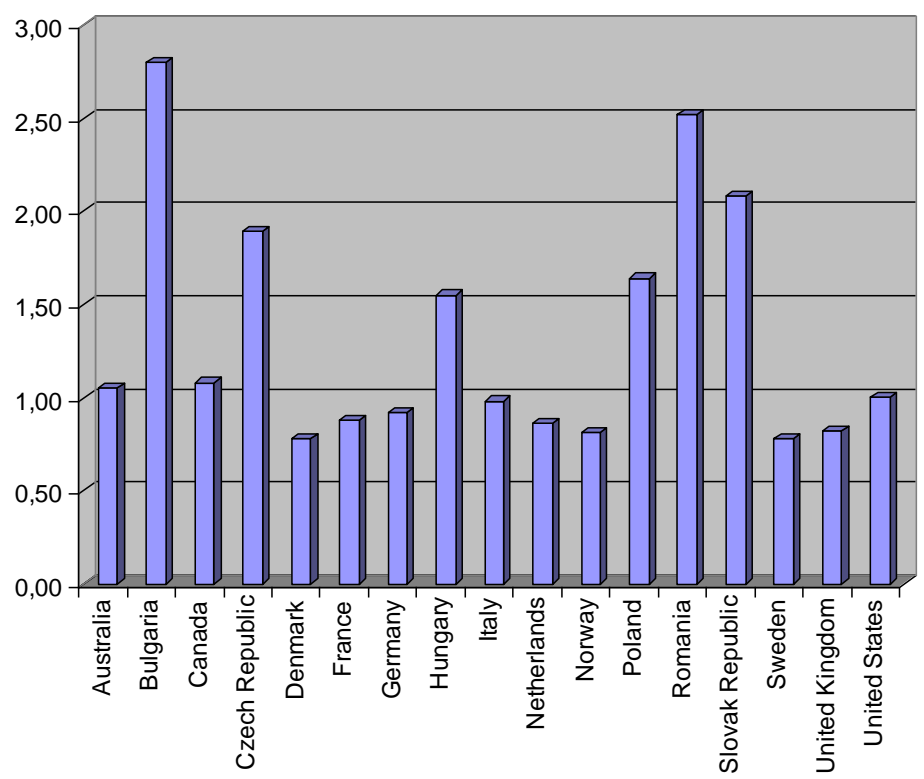

Figure 3: Purchasing Power of One US Dollar in 2005.

Therefore, we assume that capability cost (CC), expressed in defence budget per active duty military personnel in constant purchasing power parity (PPP) US dollars (Figure 4), is a function of the six defence policy parameters:

$$
C C_{P P P \$ \text { troop }}=F\left\{X_{i}\right\}, i=1, \ldots, 6,
$$

where

$$
\begin{aligned}
& X_{1}-\text { Relative power } \\
& X_{2}-\text { Technological level } \\
& X_{3}-\text { Area focus } \\
& X_{4}-\text { Mission spectrum } \\
& X_{5}-\text { Self-reliance } \\
& X_{6}-\text { Manpower attitudes. }
\end{aligned}
$$

Then, using 2005 data on the 17 countries, we approximate $F\left\{X_{i}\right\}$ by quadratic function with ten parameters that minimizes the sum of square distances to the 17 available data points. 


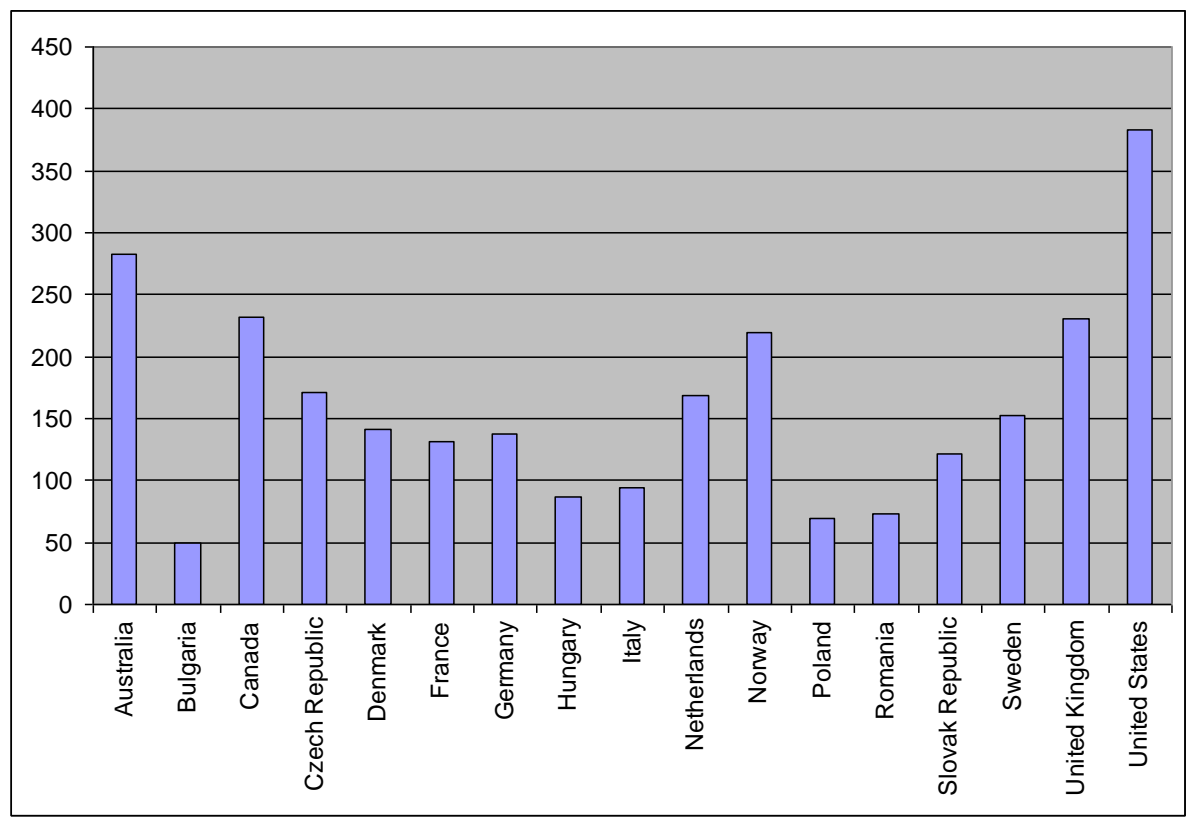

Figure 4: Defence Expenditures per Active Military Personnel, in Thousand PPP US Dollars (2005 Data).

\section{Sizing Future Armed Forces}

Once this model is designed, it can be used for variety of purposes, e.g., to support the analysis of the defence policy of a country over the years, to study policy alternatives, to support assessments of capability levels, etc. Of particular interest to the ongoing debate in Bulgaria is the size, in personnel figures, of the country's future force structure. ${ }^{8}$ Therefore we used the model to estimate what is the "reasonable" size of the Bulgarian Armed Forces in the year 2015, where "reasonable" means that the armed forces would be able to develop and maintain capabilities adequate to a selected defence policy model.

\section{Predictions and Assumptions}

This estimate is based on a number of predictions or assumptions on trends and budget levels. The following factors where identified as key for the purposes of this specific study:

1. Rate of economic growth. Bulgaria's economy is growing in the last few years with over six percent per year. Our assumption is that the GDP will continue to grow till 2015 with 5.5 to 7 percent per year. 


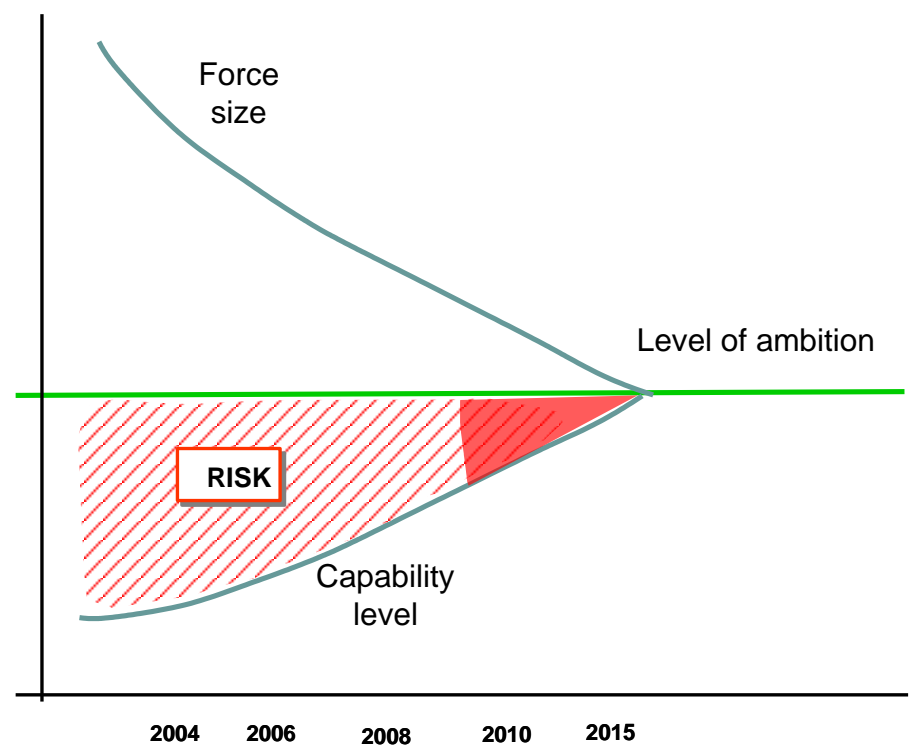

Figure 5: Closing the Capability Gap in the Process of Transformation.

2. Asymptotic increase of capabilities (and their cost). It is publicly recognized that, for example, NATO as a whole and individual countries, with the possible exception of the Unites States, lack the capabilities to achieve the levels of ambition defined in their defence policies. Current force structures still have many old heavy brigades, "hollow" formations, combat aircraft and principal naval combat ships, while lacking adequately manned deployable battalions and brigades, special purpose aircraft, strategic air and sea lift, advanced command and control, etc. The expectation is that over the years the process of transformation will close the gap between levels of defence ambitions and capability levels (see Figure 5). That will involve increase of the cost per unit of capability. Therefore, we assume that till 2015 capability costs will increase with 20 to 30 percent compared to the 2005 data.

3. Purchasing power. The purchasing power of the US dollar in Bulgaria is highest among all countries in the sample (PP multiplier of 2.8 in 2005). Our expectation is that, as a result of economic growth, social demands and the integration of the country in the European Union, by 2015 the purchasing power of the 2005 constant US dollar will decrease to a value between 1.7 and 2.

4. Purchasing power for the basket of defence goods. When applied to defence, the concept of purchasing power shall account for the specific "basket 
of defence goods." For the purposes of this study we assume that the purchasing power multiplier applies to 70 percent of defence expenditures, e.g. personnel and operations and maintenance costs, but for the other 30 percent, e.g., investments and costs of current operations, it is equal to 1.

5. Defence budget as a percentage of GDP. We do not assume a certain level of defence allocation; instead we calculate force size at two distinct levels for the 2015 defence budget -2 and 2.5 percent of the GDP.

\section{Defence Policy Alternatives}

Cost and - given the research question - the possible size of the armed forces depend on the specific defence policy of the country. Publicly available documents do not allow for a rigorous reconstruction of Bulgaria's defence policy model; therefore we need to make some additional assumptions. First, Bulgaria does not aim to increase its 'relative power' through investment in related defence capabilities. Second, the technological ambitions of the country will continue to be 'low' to 'moderate.' And third, Bulgaria's defence establishment will make some, but not decisive steps toward increasing cost efficiency through outsourcing and related initiatives.

Under these assumptions, plausible alternative defence policies differ qualitatively along the following dimensions:

- Area focus;

- Mission spectrum; and

- Manpower attitudes.

At this stage we can envision three distinct and plausible models of the Bulgaria's defence policy and the respective force structure, called tentatively "Territorial Defence Force," "Expeditionary Force," and "Force in the Service of Society."

\section{Territorial Defence Force}

This is a model of inert development of the armed forces. Considerable number of inplace organizations, such as fixed HQs and command posts, units with mainly mobilization purpose, equipment and infrastructure will be preserved. Deployability will be increased slowly and towards 2015 no more than 10 to 15 percent of the force structure will be deployable. Bulgaria will continue to send ad-hoc units, or the socalled 'contingents' to military operations out of NATO's territory. As a rule, the military will contribute to homeland/ civil security operations ad-hoc, that is with existing, not specially tailored capabilities. Interoperability will also be increased, but slowly, and there will be no clear prioritization among investments in deployable and in-place capabilities. The model is most conducive to occupational motivation and life-long career opportunities. 


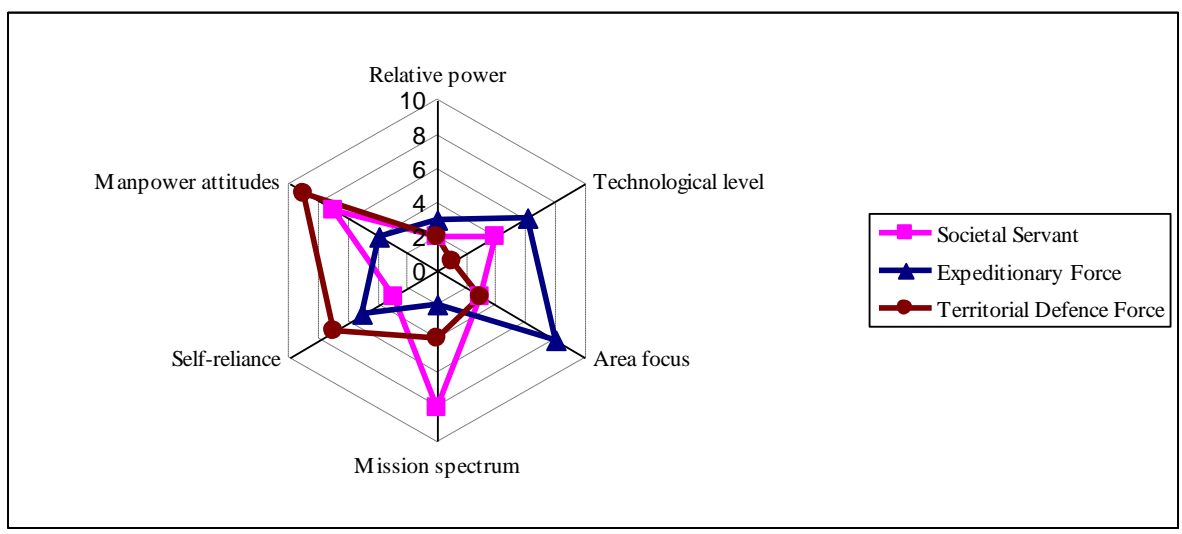

Figure 6: Plausible Defence Policies and Respective Models of the Bulgarian Armed Forces 2015.

\section{Expeditionary Force}

This model is based on a strong emphasis on deployability and contribution to out-ofarea operations. No less than 35 to 40 percent of the force structure will be deployable. The armed forces may assume air and maritime sovereignty missions in the interest of neighbouring or geographically close allies. As in the previous model, contribution to homeland/civil security will be ad-hoc. We will witness increase in the technological level and the interoperability with NATO and European Union allies. Investments will be clearly focused on deployability and related capabilities, introduction of novel concepts of operations, and interoperability. Career policy will be more flexible, and the force will be relatively younger, partially due to voluntary attrition as a result of frequent deployments to remote theatres.

\section{Force in the Service of Society}

In this model the armed forces plan for capabilities and maintain readiness to perform a broad spectrum of military missions and tasks in support of civilian population, protection of critical infrastructure, disaster relief, and the like. The country strictly meets its obligations as a reliable ally in NATO and in line with the European Security and Defence Policy. Legacy organizations, weapon systems and infrastructure are quickly eliminated. Efficiency becomes major consideration in defence management.

On the radar chart (Figure 6), the three possible models of the Bulgarian Armed Forces (BAF) are clearly distinct. The respective capabilities have different price tags and, hence, under the same set of assumptions and budget level, the force that would have adequate capabilities is of different size. 
Table 2: Reasonable Personnel Strength (Active Military, in Thousands) Depending on the Specific Defence Policy and Budget Level.

\begin{tabular}{lcc}
\hline \multicolumn{1}{c}{ Defence Budget: } & $2 \%$ GDP & $2.5 \%$ GDP \\
BAF Model & $13,5-18,7$ & $16,9-23,3$ \\
\hline Territorial Defence Force & $7,5-10,4$ & $9,4-13,0$ \\
Expeditionary Force & $9,0-12,4$ & $\mathbf{X}$ \\
Force in the Service of Society & & $(11,2-15,5)$ \\
\hline
\end{tabular}

Table 2 presents the results of reverse implementation of the model, constructed in part one of the study. As expected, the reasonable personnel strength (in thousands of active military), i.e., the force structure that provides adequate capabilities under constraints, depends on the specific defence policy model and the budget level. The highest number is just above the half of the current personnel strength of the armed forces, but that is hardly surprising, since currently Bulgaria spends a lot less per soldier (in PPP dollars), than any other of the countries in the sample.

\section{Analysis of Applicability}

Our approach has some undeniable strengths. It allows to achieve results quickly and, in our opinion, even a non-expert would with relative ease understand both the approach and the results of its implementation. It is based on comparative assessment among comparable national defence policies and cost factors and, thus, results cannot be easily disregarded. It allows a decision maker to ask and to find the answers to more focused, as well as additional 'what if,' questions.

It certainly has limitations. Most importantly, this is not and cannot be interpreted as force planning. Data is relatively limited, and the application for future force models depends on predictions in uncertain environment. The latter limitation, however, is not unique to this approach.

It provides an additional tool for analysis of alternative force structures. It can increase our understanding of alternative defence policies and be of particular value in the analysis of the impact of particular defence policy components on capability requirements and affordability. Thus, it facilitates the understanding of often implicit or seemingly unrelated executive strategies.

Among the potential outcomes from the implementation of this approach are its substantial contribution to transparency of major defence policy decisions, better com- 
munication of the executive with legislature and the public, and increasing understanding in society of what armed forces it needs and is ready to sustain. Finally, it may contribute to a discourse with more important impact on the decisions on future armed forces than any of the analytically rigorous approaches implemented by the force planning community.

\section{Conclusion}

This paper briefly summarizes a novel, theoretically sound approach to the analysis of defence policy and force models and the first results of its implementation. It is based on comparison of defence policies and cost data under the hypothesis that a particular defence policy relates to a specific set of defence capabilities with the respective impact on cost. We identified six factors, or dimensions, of defence policy with major impact on the cost of the respective capabilities, and used publicly available data to construct a model of capability cost, expressed in defence budget per active duty military personnel in constant purchasing power parity dollars, as a function of the six factors. Then the model was used to define what might be the reasonable force size of the Bulgarian Armed Forces in 2015 under three plausible alternative defence policies.

The figures presented in Table 2 shall be seen as a rough estimate, and in no way can be interpreted as a result of force planning. Nor is it a prediction. Nevertheless, while even most senior officials talk personnel numbers only, we relate defence policy, i.e., goals, ambitions, ways, etc., to required capabilities, capability levels, cost, and budget. Thus, the results presented herein may trigger and facilitate a debate on what is the adequate defence policy for Bulgaria, to assess affordability and, as a consequence, to define the size of the force.

If there is no debate or qualitative enhancements in the civilian democratic control over the armed forces, we will almost certainly witness realization of the inertial model we call "Territorial Defence Force"- it is organizationally more acceptable (preserves most positions for active duty personnel) and provides for highest numbers (which may serve a populist agenda). But it is hardly the model Bulgaria as a member of NATO and the European Union needs.

\section{Acknowledgement}

This paper reflects research on project SfP 981149 "Operations Research Support to Force and Operations Planning in the New Security Environment," sponsored by NATO's Scientific Affairs Division in the framework of the Science for Peace Program. 


\section{Notes:}

1 Conceptual developments and analysis of experience in the comprehensive approach to modern conflict are presented in the Summer 2007 edition of Connections: The Quarterly Journal, <http://consortium.pims.org>.

2 Kristian Johansen, Frank Brundtland Steder, and Espen Berg-Knutsen, "Defence Specific Inflation," preprint submitted to Defence and Peace Economics.

3 See, for example, Jack Treddenick, "Transformation and Modernization: Who Can Afford It?," presentation to The Tenth International Conference "Security and Defence Policy: New Security Challenges and the Security Sector Transformation" (Sofia: "G.S. Rakovski" Defence and Staff College, 3-4 July 2006).

4 Thomas S. Szayna, NATO Enlargement, 2000-2015: Determinants and Implications for Defense Planning and Shaping, MR-1243-AF (Santa Monica, CA: RAND Corporation, 2001), 56-59, <www.rand.org/pubs/monograph_reports/MR1243>.

5 Todor Tagarev, "Military Capabilities - National, Allied Planning and Specialization," Military Journal 110, no. 1 (2003): 35-45.

6 Some European countries, e.g. France, use the term "civil security," while others, e.g. the Scandinavian countries, prefer the term "societal security." For detailed discourse refer to vol. 17 of "Information \& Security," < http://infosec.procon.bg>.

7 See for example, NATO's defence expenditures database, <www.nato.int/issues/defence_expenditures/index.html>, and the Purchasing Power Parities (PPP) Statistics provided by the Organization of Economic Cooperation and Development (OECD) and Eurostat, <www.oecd.org/topicstatsportal/0,3398,en_2825_ 495691_1_1_1_1_1,00.html>.

8 For example, in an interview at the end of August 2007, the Prime Minister of Bulgaria HE Sergey Stanishev stated that the armed forces of the country should be downsized to approximately 24,000 . No additional information was provided in that interview or its aftermath.

TODOR TAGAREV - Information about the author is available on page 114 of this volume.

LIDIA VELKOVA is with the Defence and Force Management Department of the "G.S. Rakovski" Defence and Staff College, Sofia, Bulgaria, since its establishment. She is a graduate of the University of National and World Economy in Sofia and received a Ph.D. degree from the "G.S. Rakovski" Defence and Staff College in 2004. Dr. Velkova is experienced professor with primary research interests in the areas of economic security and organisational processes in the defence administration. She has published more than 20 papers is refereed journals. E-mail: liwel@abv.bg. 